\title{
IMPLEMENTASI METODE OPTIMALISASI JUMLAH PRODUKSI DENGAN MENGGUNAKAN LINIER PROGRAMMING
}

\author{
Mujiono'), Sujianto $^{2)}$ \\ ${ }^{1), 2)}$ Dosen Teknik Industri, Institut Teknologi Nasional Malang \\ E-mail : jiono1864@gmail.com
}

\begin{abstract}
Abstrak, Optimalisasi bisa diartikan untuk mengeffisien dan mengeffektifkan hasil produksi dimiliki oleh perusahaan dengan cara selalu berusaha meningkatkan profit yang sangat besar dengan menekan cost serendah mungkin. Sedangkan Linier Programming adalah suatu teknik matematik yang didesain untuk membantu para manajer operasi dalam merencanakan dan membuat keputusan yang diperlukan untuk mengalokasikan sumber daya yang ada. Model matematika mewakili sebuah system secara komplek dimana factor factor akan dianalitis . Ia menunjukkan hubungan-hubungan (langsung maupun tidak langsung) dari suatu aksi dan reaksi dalam pengertian sebab akibat. Sebab sebuah model adalah suatu abstraksi realitas, ia akan tampak kurang komplek dibandingkan realitas itu sendiri. Model tersebut agar supaya menjadi lengkap perlu mencerminkan semua realitas yang sedang diteliti. Penelitian ini bertujuan untuk menentukan jumlah yang harus diproduksi dengan metode simplek, agar supaya target perusahaan dapat terpenuhi dengan menekan cost produksi serendah mungkin dan meningkat profit dengan menggunakan program Quantitatif Manajemen(QM/POM) diperoleh $x_{1}=N P L 330 \mathrm{ml}$ yang seharusnya diproduksi sebanyak 54000 box/hari, $x_{2}=N P L 600 \mathrm{ml}$ yang seharusnya diproduksi sebanyak 48000 box/hari, $x_{3}=N P L 1500 \mathrm{ml}$ yang seharusnya diproduksi sebanyak 30000 box/hari. Dengan keuntungan : Rp. 932.599.000.
\end{abstract}

Kata Kunci : Optimasi, Linier Programming

\section{PENDAHULUAN}

Optimalisasi adalah mengefektifkan dan mengeffisienkan sumberdaya yang ada dalam perusahan sehingga dapat menekan biaya dan meningkatkan keuntungan. Linier Programing merupakan teknik matematik dimana didesain dipergunakan para manajer operasi dalam merencanakan dan membuat keputusan yang diperlukan untuk mengalokasikan sumber daya yang ada. (Operations Management, Jay Heizer,Barry Render, hal. 588).

\section{Optimalisasi}

Optimalisasi bisa diartikan untuk mengeffisien dan mengeffektifkan hasil produksi dimiliki oleh perusahaan dengan cara selalu berusaha meningkatkan profit yang sangat besar dengan cara menekan cost serendah rendah mungkin demikelangsungan hidup perusahaan.

\section{Pengertian Linier Programming}

Sedangkan Linier Programming adalah suatu teknik matematik yang didesain untuk membantu para manajer operasi dalam merencanakan dan membuat keputusan yang diperlukan untuk mengalokasikan sumber daya yang ada. (Operations Management, Jay Heizer, Barry Render, hal. 588).

Pemodelan merupakan suatu representasi atau formalisasi dalam bahasa tertentu yang disepakati dari suatu sistem nyata. Sistem nyata yang dimaksud adalah sistem yang sedang berlangsung dalam kehidupan, sistem yang dijadikan titik perhatian dan dipermasalahkan pemodelan. Sedangkan pemodelan merupakan proses membangun atau membentuk sebuah model dari suatu sistem nyata dalam bahasa formal model tertentu. Menunjukkan hubungan-hubungan (langsung maupun tidak langsung) dari suatu aksi dan reaksi dalam pengertian sebab akibat. Sebab sebuah model adalah suatu abstraksi realitas, ia akan tampak kurang komplek dibandingkan realitas itu sendiri. Model tersebut agar supaya menjadi lengkap perlu mencerminkan semua realitas yang sedang diteliti.

\section{Formula Model LP}

Maksimalkan:

$\mathrm{Z}=\mathrm{C}_{1} \mathrm{X}_{1}+\mathrm{C}_{2} \mathrm{X}_{2}+\mathrm{C}_{3} \mathrm{X}_{3}+\ldots+\mathrm{C}_{\mathrm{n}} \mathrm{X}$

Bentuk Standar Fungsi Batasan:

$a_{11} X_{1}+a_{12} X_{2}+a_{13} X_{3}+\ldots+a_{1 n} X_{n} \leq b_{1}$ 
$a_{21} X_{1}+a_{22} X_{2}+a_{23} X_{3}+\ldots+a_{2 n} X_{n} \leq b_{2}$ $a_{m 1} X_{1}+a_{m 2} X_{2}+a_{m 3} X_{3}+\ldots+a_{m n} X_{n} \leq b_{m}$ $\mathrm{X}_{1} \geq 0$

- $\mathrm{m}=$ macam batasan-batasan fasilitas yang tersedia

- $\mathrm{n}=$ macam kegiatan yang menggunakan fasilitas

- $\mathrm{I}=$ nomor fasilitas yang tersedia ( $\mathrm{i}=1,2,3, \ldots, \mathrm{n}$ )

- $\mathrm{j}=$ nomor kegiatan yang menggunakan fasilitas tersedia $(j=1,2,3, \ldots, m)$

- $\mathrm{X}_{\mathrm{i}}=$ tingkat kegiatan $\mathrm{i},(\mathrm{i}=1,2,3, \ldots, \mathrm{n})$

- $a_{i j}=$ banyaknya sumber $\mathrm{i}$ yang diperlukan untuk menghasilkan setiap unit kegiatan $\mathrm{j},(\mathrm{i}=1,2,3, \ldots, \mathrm{n})($ $\mathrm{j}=1,2,3, \ldots, \mathrm{m}$ )

- $b_{i}=$ banyaknya fasilitas $i$ yang tersedia untuk dialokasikan ke setiap unit kegiatan i, ( $\mathrm{i}=1,2,3, \ldots, \mathrm{n})$

- $\mathrm{Z}=$ nilai yang dioptimalkan (maksimumkan)

- $\mathrm{Cj}=$ kenaikan nilai $\mathrm{Z}$ bila ada pertambahan satu satuan kegiatan $\left(\mathrm{x}_{\mathrm{j}}\right)$

Dengan syarat : $a_{i j} x_{j}(\leq,=, \geq) b_{i}$ untuk semua $\mathrm{i}$ $(\mathrm{i}=1,2,3, \ldots \mathrm{m})$ semua $x_{j} \geq 0$ dimana :

$\mathrm{X}_{\mathrm{j}}=$ banyaknya kegiatan $\mathrm{j}$, dimana $\mathrm{j}=1,2, \ldots \ldots \mathrm{n}$ ,berarti terdapat $n$ variable keputusan.

$\mathrm{Z}$ = nilai fungsi tujuan.

$\mathrm{C}_{\mathrm{j}}=$ sumbangan per unit kegiatan, untuk masalah maksimisasi $\mathrm{C}_{\mathrm{j}}$ menunjukkan keuntungan atau penerimaan per unit, sementara dalam minimisasi $\mathrm{C}_{\mathrm{j}}$ menunjukkan biaya per unit.

$b_{i}=$ jumlah sumber daya $i(i=1,2, \ldots m)$.

$\mathrm{a}_{\mathrm{ij}}=$ banyak sumber daya $\mathrm{i}$ yang dikonsumsi sumber daya $\mathrm{j}$.

\section{Metode Simplek}

Metode simplek adalah suatu metode yang digunakan untuk menentukan kombinasi optimal dari tiga variabel atau lebih. Sedangkan apabila hanya mengandung dua varibel saja maka akan dengan mudah diselesaikan dengan menggunakan metode garafik. Di dalam metode simplek yang akan kita lakukan mulamula menjelaskan langkah langkah penyelesaikan persoalan yang dapat diformulasikan dalam bentuk standar, karena bentuk tersebut yang akan lebih mudah diselesaikan, selanjutnya kita lanjutkan jika formulasinya menyimpang dari bentuk standar.
Ada beberapa istilah yang sangat sering digunakan dalam metode simpleks, diantaranya Iterasi adalah tahapan perhitungan dimana nilai dalam perhitungan itu tergantung dari nilai tabel sebelumnya.

Variabel non basis adalah variabel yang nilainya diatur menjadi nol pada sembarang iterasi. Dalam terminologi umum, jumlah variabel non basis selalu sama dengan derajat bebas dalam sistem persamaan.

Variabel basis merupakan variabel yang nilainya bukan nol pada sembarang iterasi. Pada solusi awal, variabel basis merupakan variabel slack (jika fungsi kendala merupakan pertidaksamaan $\leq$ ) atau variabel buatan (jika fungsi kendala menggunakan pertidaksamaan $\geq$ atau $=$ ). Secara umum, jumlah variabel basis selalu sama dengan jumlah fungsi pembatas (tanpa fungsi non negatif).

Solusi atau nilai kanan merupakan nilai sumber daya pembatas yang masih tersedia. Pada solusi awal, nilai kanan atau solusi sama dengan jumlah sumber daya pembatas awal yang ada, karena aktivitas belum dilaksanakan.

Variabel slack adalah variabel yang ditambahkan ke model matematik kendala untuk mengkonversikan pertidaksamaan $\leq$ menjadi persamaan (=). Penambahan variabel ini terjadi pada tahap inisialisasi. Pada solusi awal, variabel slack akan berfungsi sebagai variabel basis.

Variabel surplus adalah variabel yang dikurangkan dari model matematik kendala untuk mengkonversikan pertidaksamaan $\geq$ menjadi persamaan (=). Penambahan ini terjadi pada tahap inisialisasi. Pada solusi awal, variabel surplus tidak dapat berfungsi sebagai variabel basis.

Variabel buatan adalah variabel yang ditambahkan ke model matematik kendala dengan bentuk $\geq$ atau = untuk difungsikan sebagai variabel basis awal. Penambahan variabel ini terjadi pada tahap inisialisasi. Variabel ini harus bernilai 0 pada solusi optimal, karena kenyataannya variabel ini tidak ada. Variabel hanya ada di atas kertas.

Kolom kunci (kolom kerja) adalah kolom yang memuat variabel masuk. Koefisien pada kolom ini akn menjadi pembagi nilai kanan untuk menentukan baris kunci(baris kerja).

Baris kunci (baris kerja) adalah salah satu baris dari antara variabel basis yang memuat variabel keluar. 
Elemen kunci (elemen kerja) adalah elemen yang terletak pada perpotongan kolom dan baris kunci. Elemen kunci akan menjadi dasar perhitungan untuk tabel simpleks berikutnya.

Variabel masuk adalah variabel yang terpilih untuk menjadi variabel basis pada iterasi berikutnya. Variabel masuk dipilih satu dari antara variabel non basis pada setiap iterasi. Variabel ini pada iterasi berikutnya akan bernilai positif.

Variabel keluar adalah variabel yang keluar dari variabel basis pada iterasi berikutnya dan digantikan oleh variabel masuk. Variabel keluar dipilih satu dari antara variabel basis pada setiap iiterasi. Variabel ini pada iterasi berikutnya akan bernilai nol.

\section{Model Umum Metode Simpleks.}

\section{Kasus Maksimisasi.}

$$
\begin{aligned}
& \text { Fungsi Tujuan : Maksimumkan } \\
& \mathrm{Z}-\mathrm{C}_{1} \mathrm{X}_{1}-\mathrm{C}_{2} \mathrm{X}_{2}-\ldots \ldots-\mathrm{C}_{\mathrm{n}} \mathrm{X}_{\mathrm{n}}-0 \mathrm{~S}_{1}-0 \mathrm{~S}_{2-} \ldots- \\
& 0 \mathrm{~S}_{\mathrm{n}}=\mathrm{NK}
\end{aligned}
$$

Fungsi Pembatas :

$$
\begin{aligned}
& a_{11} X_{11}+a_{12} X_{12}+\ldots+a_{1 n} X_{n}+S_{1}+0 S_{2}+\ldots+0 S_{n}= \\
& b_{1} \\
& a_{21} X_{21}+a_{22} X_{22}+\ldots+a_{2 n} X_{n}+0 S_{1}+1 S_{2}+\ldots+0 S_{n} \\
& =b_{2} \\
& a_{m 1} X_{m 1}+a_{m 2} X_{m 2}+\ldots .+a_{m n} X_{n}+S_{1}+0 S_{2}+. \\
& +1 S_{n}=b_{m}
\end{aligned}
$$

\section{Langkah Metode simplek}

1. Mengubah fungsi tujuan dengan batasan batasan fungsi ketidaksamaan ini harus diubah menjadi kesamaan, caranya dengan menambah slack variable.

Variable slack ini adalah

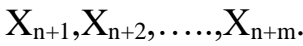

Karena tingkat atau hasil kegiatan-kegiatan yang ada diwakili oleh $\mathrm{X}_{1}$ dan $\mathrm{X}_{2}$, maka variable slack dimulai dari $\mathrm{X}_{3}, \mathrm{X}_{4}$ dan seterusnya.

2. Menyusun persamaan persamaan di dalam table.

Setelah formulasi diubah kemudian disusun kedalam table sbb :

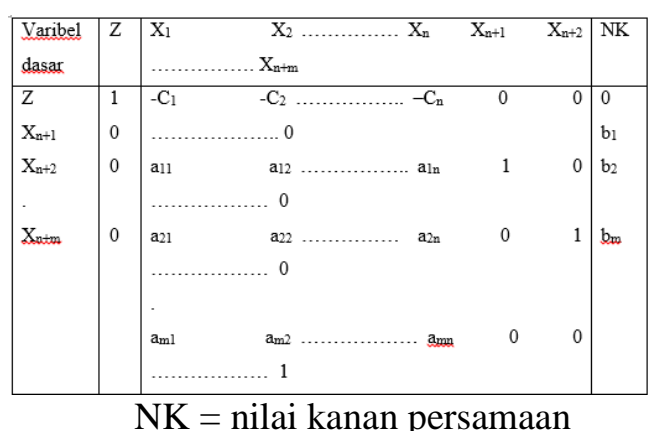

3. Membuat Kolom kunci

Dalam hal ini yang kita lakukan adalah mencari kolom yang memiliki nilai negatif paling besar.

4. Membuat baris kunci dalam menyelesaikan masalah

Membuat baris kunci dalam masalah ini adalah dengan menggunakan rumus dibawah.

$$
\text { Indeks }=\frac{\text { Nilai kolom } N K}{\text { Nilai kolom kunci }}
$$

5. Merubah baris kunci.

Dilakukan dengan membagi dengan hasil angka kunciyang diperoleh

6. Meneruskan nilai perubaha. nilai perubahan dilakukan mengikuti langkah diatas.

Pendekatan khusus dalam linier programmning. dalam menentukan berapa yang seharusnya diproduksi agar supaya mendapatkan keuntungan yang maksimal.

Tujuan penelitian ini adalah :

- Untuk mengetahui berapa jumlah yang seharusnya diproduksi.

- Sebagai acuan untuk pengambilan keputusan memaksimumkan keuntungan bagi perusahaaan.

- Penyelesaian yang menggunakan metode simplek atau menggunakan program.

- Menggunakan program QM.

- Menentukan model yang sesuai. 


\section{METODE}

\section{Metode Pengumpulan Data}

Metode pengumpulanlan data antara lain:

1. Observasi

Melakukan pengambilan data padaperusahaan saat produksi berlangsung

2. Interview

Pengumpulan data dilakkan dengan cara melakukan pertanyaan secara langsung kepada bagian produksi.

3. Pengumpulan Data

Data yang diperlukan dalam penelitian ini diantaranya data jumlah yang akan produksi dan juga keuntungannya berapa yang diharapkan oleh umkn dengan liniering programming dengan menggunakan metode simplek dan dibanding dengan menggunakan program QM.

\section{HASIL DAN PEMBAHASAN Hasil Penelitian}

Hasil Penyelesaian masalah dalam penelitian ini menggunakan linier programming yang mempunyai tiga unsur utama yaitu :variabel keputusan, fungsi tujuan dan fungsi kendala. Variabel keputusan merupakan ketiga jenis produk yang diproduksi oleh perusahaan. Fungsi tujuan adalah fungsi untuk memperoleh keuntungan sedangkan fungsi kendala adalah proses produksi yang harus dilalui yaitu : MWTP (mesin water treatment procces pak,MFC (mesin filing and capping,ML (mesin labeling, dan MV mesin variopack) dengan permintaan masing masing (dalam ribuan) : 54 , 214 dan 161 box.

1. Variabel Keputusan:

$$
x_{1}=N P L 330 \mathrm{ml}, x_{2}=N P L 600 \mathrm{ml}, x_{3}=N P L 1500 \mathrm{ml}
$$

2. Fungsi Tujuan :

$$
\max =5500 x_{1}+7500 x_{2}+9000 x_{3}
$$

3. Fungsi Kendala :

$$
\begin{aligned}
& \text { MWTP }: 217 x_{1}+168 x_{2}+170 x_{3} \leq 25000 \\
& \text { MFC }: 245 x_{1}+388 x_{2}+253 x_{3} \leq 46000 \\
& M L: 30 x_{1}+73 x_{2}+94 x_{3} \leq 8000 \\
& M V: 45 x_{1}+65 x_{2}+250 x_{3} \leq 15000 \\
& \text { Permin taan: } \quad x_{1} \quad \leq 54 \\
& \text { Permin taan: } \quad x_{2} \quad \leq 214 \\
& \text { Permin taan: } \quad x_{3} \quad \leq 161 \\
& x_{1}, x_{2}, x_{3} \quad \geq 0
\end{aligned}
$$

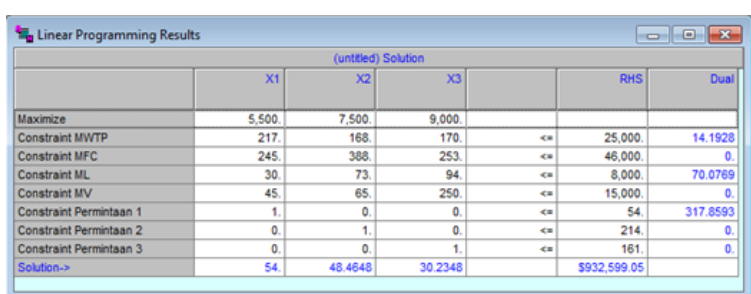

- Pembahasan Hasil Penelitian

\section{Pembahasan}

Model matematik yang diperoleh dari hasil penelitian ini adalah :

1. Fungsi Tujuan

Fungsi tujuan dalam hal ini adalah untuk menentukan keuntungan secara maksimum

2. Fungsi batasan

Batasan pertama :

$217 x_{1}+168 x_{2}+170 x_{3} \leq 25000 \mathrm{~B}$ atasan kedua

$$
245 x_{1}+388 x_{2}+253 x_{3} \leq 46000 \mathrm{~b}
$$

atasan ketiga

$$
30 x_{1}+73 x_{2}+94 x_{3} \leq 8000
$$

Batasan keempat

$$
45 x_{1}+65 x_{2}+250 x_{3} \leq 15000
$$

Batasan kelima,enam dan tujuh masing-masing :54, 214 dan 161.

$$
Z_{\text {max }}=5500 x_{1}+7500 x_{2}+9000 x_{3}
$$

s.t

$$
\begin{gathered}
217 x_{1}+168 x_{2}+170 x_{3} \leq 25000 \\
245 x_{1}+388 x_{2}+253 x_{3} \leq 46000 \\
30 x_{1}+73 x_{2}+94 x_{3} \leq 8000 \\
45 x_{1}+65 x_{2}+250 x_{3} \leq 15000
\end{gathered}
$$

$$
\begin{aligned}
x_{1} & \leq 54 \\
x_{2} & \leq 214 \\
x_{3} & \leq 161 \\
x_{1}, x_{2}, x_{3} & \geq 0
\end{aligned}
$$

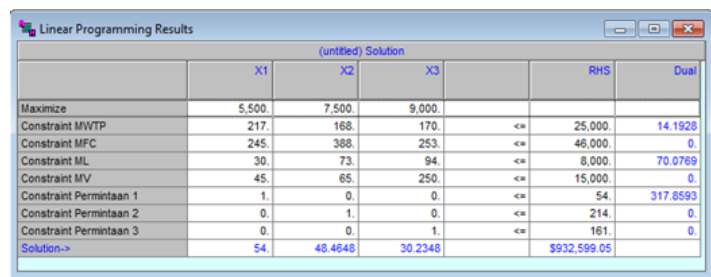

Hasil pembahasan :

$x_{1}=N P L 330 \mathrm{ml}$

yang seharusnya diproduksi sebanyak 54000 box/hari.

$x_{2}=N P L 600 \mathrm{ml}$ 
yang seharusnya diproduksi sebanyak 48000 box/hari.

$x_{3}=N P L 1500 \mathrm{ml}$

yang seharusnya diproduksi sebanyak 30000 box/hari.

Dengan keuntungan : Rp. 932.599.000.

\section{KESIMPULAN}

Berdasarkan hasil penelitian diatas dapat disimpulkan bahwa :

1) Model matematika dari fungsi tujuan diperoleh

$Z_{\text {max }}=5500 x_{1}+7500 x_{2}+9000 x_{3}$

Dengan batasan masing-masing

Batasan pertama :

$217 x_{1}+168 x_{2}+170 x_{3} \leq 25000$

Batasan kedua

$245 x_{1}+388 x_{2}+253 x_{3} \leq 46000$

batasan ketiga

$30 x_{1}+73 x_{2}+94 x_{3} \leq 8000$

Batasan keempat

$45 x_{1}+65 x_{2}+250 x_{3} \leq 15000$

Batasan kelima,enam dan tujuh masingmasing :54, 214 dan 161.

2) Hasil produksi

$x_{1}=$ NPL $330 \mathrm{ml}$

sebanyak 54.000 Box/hari,

$x_{2}=N P L 600 \mathrm{ml}$

sebanyak 48000 box/hari.

$x_{3}=N P L 1500 \mathrm{ml}$

sebanyak 30000 box/hari.
Dengan keuntungan :

Rp. 932.599.000.

\section{DAFTAR PUSTAKA}

Jay Heizer, Barry Render. 2018. Operations Management, edition $9^{\text {th }}$, ISBN 450-417628-909-7, hal. 588).

Agustina, Erni. 2010. Analisis Optimalisasi Produksi dengan Metode Linier Programming.

T. Windarti, 2013. Pemodelan Optimalisasi Produk untuk Memaksimalkan Keuntungan dengan menggunakan Metode Program Linier. (Jurnal ilmiah Pengetahuan dan Penerapan Teknik Industri) vol.11, no. 2, pp. 150-159.

Mokhtar S, Bazaraa, John J.Jarvis dan Hanif D Sherali. 2010. Linier Programming and Network Flows,Jon Wiley \& Sons,.

Ainul M. 2017. Optimalisasi Keuntungan dalm Produksi dengan menggunkana Linier Programming. Lampung. Universitas Islam Negeri raden Intan Lampung.

Ibnas, Risnawati 2014. Optimalisasi kasus Program Linier dengan Metode Grafik dan Simplek. Jurnal MSA Vol.2 No.1 ED. Jan-Juni 2014.

Philip, Don T Ravidran, Solberg James. 1979. Operation Research Principles and Practice. New York:John Willey \& Sons.

Stapleton,D.M., Hanna,J.B \& Markussen,D.2003. Marketing Strategy Optimization: User Linier Programming To Establish An Optimal Marketing Mixture. American Business Review,21(2),54-62. 